\title{
CORRESPONDENCE
}

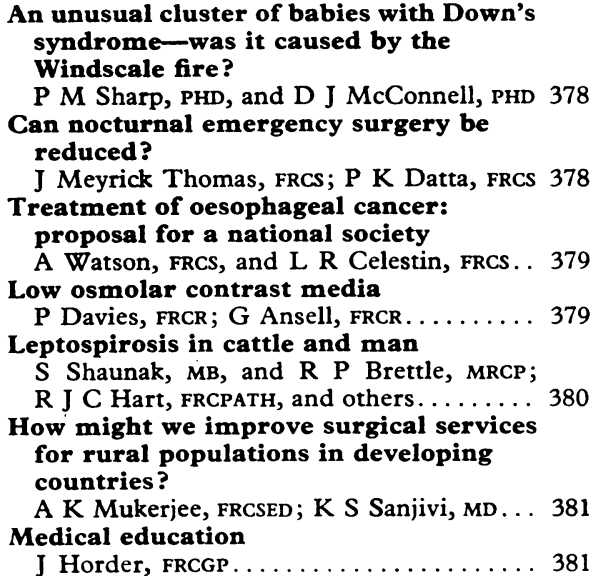

Private rest homes

J Snape, MRCP.................. 381

Appalled junior surgeons at $\mathrm{St}$ Thomas's Hospital

P A E Hurst, FRCs . . . . . . . . . . . . . . . 382

Preregistration house officer posts

P Thornton.................. 382

Parental consent for examining girls under 16

C R Lynn, LMSSA.

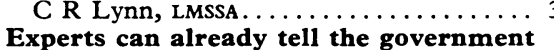
Experts can already tell the government
why children smoke: no psychiatrist needed

S Chapman, BA, and F Ledwith, PHD...

Points Too many copies required of a doctor's curriculum vita (A J McIrvine); Junior job hunting ( $T$ Hilary Howells); Cardiac arrest after apparent recovery from an overdose of chlorpromazine (D M an overdose of chlorpromazine (D M (M Drury); Major ocular trauma in field hockey (P T McCollum); Rifampicin in non-tuberculous infections (W H Jopling); Washing after a stroke (A D Bateman); Inhalation devices for asthma (A J Johnson); Non-specificity of surfactant deficiency in neonatal respiratory disorders (D K James); Bad case notes (C Hawkins); Drugs and porphyria (A G Yalouris) ........... 383 The other stretch reflex ( $\mathrm{T} J$ Steiner); Late mortality after vagotomy and drainage for duodenal ulcer (C Caygill and others); Violence and mental illness ( $M$ Weller); Doctor to doctor (N Evans and others); Patient misinformation (G B Carter); Autoimmune thyroid disease and pregnancy (R T Cooke); Switching from private to NHS treatment (C R Bayliss); Medical indemnity ( $\mathrm{R}$ Jandoo); Epilepsy and the law (J McCluggage); GMC and the recognition of overseas postgraduate diplomas (Sir John Crofton)......... 384

We may shorten letters to the editor unless the authors specifically state that we may not. This is so that we can offer our readers as wide a selection of letters as possible. We receive so many letters each week that we have to omit some of them. Letters must be typed with double spacing between lines and must be signed personally by all their authors, who should include their degrees. Letters critical of a paper may be sent to the authors of the paper so that their reply may appear in the same issue.

Correspondents should present their references in the Vancouver style (see examples in these columns). In particular, the names and initials of all authors must be given unless there are more than six, when only the first three should be given, followed by et al; and the first and last page numbers of articles and chapters should be included.

\section{An unusual cluster of babies with Down's syndrome-was it caused by the Windscale fire?}

SIR,-Dr Patricia M E Sheehan and Professor Irene $B$ Hillary speculated that radiation released by the Windscale fire on 10 October 1957 might have been partly responsible for a cluster of births of babies with Down's syndrome (all trisomy-21) to six women who were all at one school in Dundalk, Ireland, in 1957 (12 November 1980, p 1428). Subsequent correspondence left the significance of this finding unresolved (14 January, $p$ 146). Three points must be addressed: (1) Might this cluster of babies with Down's syndrome have occurred by chance? (2) Did any radiation from the cloud reach Ireland ? (3) Is radiation known to increase the incidence of aneuploidy -for example, trisomy-21-in man?

Dr W H James (14 January, p 147) suggested that the cluster could have occurred by chance, but the data available to him were incomplete. The number of babies with Down's syndrome was ultimately reported as eight (14 January, p 147), and the number of births to girls who were at the school in 1957 was less than 400 . Since none of the women was over 32 at the time of the birth of their child with Down's syndrome the expected incidence is approximately 1 in $1200 .{ }^{1}$ Fewer than one in 60 million groups of 400 births would be expected to contain a cluster of more than seven babies with Down's syndrome so this is certainly a significant cluster.
Dr A P Brown (14 January, $p$ 147) raised contemporary reports suggesting that it is unlikely that any radioactivity from Windscale reached Ireland. The only way in which remnants of the cloud might have reached Dundalk is by a very roundabout route. Meteorological reports show that the airstream which arrived over Ireland on 15 October 1957 could have originated a couple of days earlier over the South of England (personal communication from W G Callaghan, Irish Meteorological Service), where iodine-131 ("the only material of biological significance" in the cloud') from the Windscale fire was recorded. Of course by 15 October the radioactivity would have diffused greatly. The Irish Meteorological Service received a request from the advisory committee on nuclear radiation in de Bilt, the Netherlands, for the filter papers exposed daily at Dublin and Valentia, Kerry, during 10-16 October 1957. Detailed analycis of their radioactive contents by $\gamma$ ray spectrometer showed no important amount of iodine-131 (personal communication from W G Callaghan, Irish Meteorological Service).

Finally Bond and Chandley have concluded that in man "for aneuploidy induction by irradiation, the data would indicate that the risk of inducing trisomy is very small," 8 and there is no evidence relating to the suggested interaction between a low level of radiation and viral infection (12 November, $p$ 1428). In conclusion, there is no evidence that radiation from the Windscale accident might have reached Ireland and the only factor implicating it in the causation of these genetic accidents is the coincidence of timing. The cluster did not occur by chance but requires an alternative explanation.

Paul M Sharp DAVID J MCCONNELI

Department of Genetics,

Trinity College,

Smith GF, Berg JM. Down's anomaly. Edinburgh Churchill Livingstone, 1976

Chamberlain AC, Dunster HJ. Deposition of radioDeflioat Windscale. Nature 1958;182:629-30

3 Bond DJ, Chandley AC Aneuploidy. Oxford: Oxford University Press, 1983:117.

\section{Can nocturnal emergency surgery be} reduced?

SIR,-All surgeons will be interested in the findings of $\mathrm{Mr} \mathrm{D} \mathrm{J}$ Sherlock and others (21 July, p 170), but I suggest that it is widely appreciated, although rarely admitted, that most emergency operations are performed at night for convenience rather than necessity. 
I was surprised to see that $\mathrm{Mr}$ Sherlock and others considered that none of the appendicectomies could safely have been deferred to the next day. Except for the very occasional case operated on at night for convenience, my practice is not to remove appendices during the night, and in over 400 cases I have not had cause to regret this policy. While we rightly deprecate the use of antibiotics in undiagnosed acute abdominal pain, I start treatment with metronidazole (as well as analgesia) once I have diagnosed appendicitis, and my decision to remove the appendix is not swayed by the-often dramatic -overnight response to treatment.

Most cases of intestinal obstruction and gastrointestinal bleeding, all cases of "biliary conditions," and even cases of perforated peptic ulcer may not only safely be deferred to the following day but will also benefit from overnight rehydration, correction of electrolyte imbalance, and nasogastric decompression of the gut. These measures inevitably tend to be curtailed at night when everyone wants to operate and get to bed. I consider therefore that probably only 70 (and possibly fewer) of the cases reported by $\mathrm{Mr}$ Sherlock and others required night time operation, which has important implications.

The reason for operating at night is the lack of money available to pay staff in busy district general hospitals to cover additional operating sessions on a regular basis for deferred emergencies. Those hospitals which run three or four "trauma lists" a week for fractured hips and deferred internal fixation of other fractures testify to the success of such a policy in freeing operating theatres at night for general surgical emergencies. With the present staffing structure of NHS hospitals, however, day time operating for all is a luxury which the NHS cannot afford; indeed, a shift system for deliberate night time emergency surgery by training surgeons desperate for experience might provide the most efficient use of operating theatres.

If, however, the proposals of the Short report are implemented, there will be no junior surgeons to operate through the night Are consultants justified in their fears that they will end up supporting an underpriced NHS by working day and night until their retirement to keep pace with demand? I am sure that the "powers that be" would like to think they would, but I am equally certain that what would happen is that each night covered by a consultant would be followed by a vacant operating session to deal with the night's harvest of deferred emergencies. Most of the time, as my modified conclusions from the findings of $\mathrm{Mr}$ Sherlock and others suggest, the consultant will get a decent night's sleep and the house surgeon will get a far better grounding in the assessment of surgical emergencies than she does now, which should result in better surgically trained general practitioners. The loss of one elective operating session for each night on take would, of course, result in lengthened waiting lists, quite properly reflecting the government's reluctance to provide enough money for the NHS to function as its subscribers wish.

\section{J MEYRICK THOMAS}

Royal Free Hospital,
London NW3 2QG

SIR,-The paper on nocturnal emergency surgery has touched on all relevant factors except one. I suspect this factor has not been mentioned as accurate statistics cannot be produced without an enormous amount of heart searching on the part of the trainee and some embarrassment on the part of the consultant. The factor is that a few surgeons in training do emergency operations which could easily wait simply because they know that if they leave these patients to be operated on next morning they will find themselves at the end of a retractor while the consultant does the operation.

The remedy is for consultants to make sure that their trainees get enough elective operating to do. They should also be prepared to come in for an emergency and take their registrar through the operation instead of "taking over" the operation themselves. Furthermore, if the registrar knows that he will be taken through a major emergency operation by a senior colleague next morning he will certainly leave patients who can waitwith benefit to the patient. Only with such a practice will the patient get the best deal and nocturnal emergency surgery be reduced.

Pradip K Datta

Bignold Hospital

Wick, Caithness KW 1 4DL

Treatment of oesophageal cancer: proposal for a national society

SIR,-Mr Richard Earlam's account of the management of oesophageal cancer in the North East Thames region (23 June, $p$ 1892), though no doubt reflecting current practice, makes depressing reading from which three important conclusions are apparent. Firstly, when a major specialised operation is undertaken on an occasional basis in centres without the coordinated multidisciplinary approach of specialised units the outcome is abysmal. Secondly, the results are so different from those obtained in these units that it is clear there exist fundamental differences in philosophy, selection, and practical management of a disorder that is uncommon. Finally, data obtained either from many outdated series or even from pooled hospital activity analyses are less valid in assessing our current achievement than prospective analysis of data from specialist units.

The first objective with oesophageal cancer must be to render the patient euphagic and obviate an unpleasant death from starvation. The second is to offer a cure in selected patients. The third objective is to accomplish the above in a humane manner and with morbidity and mortality which is both clinically and ethically acceptable. The attainment of these objectives requires careful selection by a few doctors choosing the treatment without bias and after objective assessment of spread and operability. It demands a multidisciplinary approach with physicians, surgeons, radiologists, anaesthetists, radiotherapists, and oncologists employing proved advances in assessment, preoperative preparation, operative techniques, and postoperative care, together with careful documentation, follow up of patients, and continuing review of results.

The documentation and analysis of results become more meaningful if these are from a well defined catchment population as has been the experience in Lancaster. It has one of the highest incidences in the United Kingdom, and 186 patients with oesophageal carcinoma have been treated over the past 10 years. Resection has been deemed appropriate in about $40 \%$, with a resectability rate of $95 \%$ of those operated on. ${ }^{1}$ The procedure related mortality (hospital and 30 day mortality) has been $10 \%$ overall, falling to $5.5 \%$ in the last two years. The mean time to death in those not surviving resection was 11.5 days; no procedure related deaths occurred after 30 days, and very few patients stayed in hospital for this length of time. Survival at one year was $5 \%$ and at five years $10 \%$, although this latter figure is conservative as some patients remain alive two to four years after the resection. Every patient referred had fibreoptic endoscopy with a biopsy and brush cytology as an outpatient, and no one was denied a therapeutic procedure. Over $90 \%$ of those discharged from hospital who have since died have done so outside the acute hospital. Most were with their families, who were supported by general practitioners, a 24 hour district nursing service, and an oncology health visiting service.

All of these figures are very different from those of $\mathrm{Mr}$ Earlam's review, but are by no means confined to our own units. Very similar figures for operative mortality and survival have been published recently by Dark $e t a l^{2}$ and McKeown. ${ }^{3}$ We maintain that a nihilistic approach should not be adopted merely because the potential for therapeutic disaster appears to be so great. We believe that no patient should be denied the chance of a cure. Equally he should not be made to incur an unacceptable risk by being subjected to inappropriate surgical intervention; neither should a lesser procedure such as intubation be a substitute for well performed surgery on the grounds that the former carries a lesser mortality. Our experience has shown this is not the case, and resection in appropriate cases is the only treatment to achieve euphagia in over $90 \%$ of cases. ${ }^{4}$

What is now required is the centralisation of treatment of these patients in specialist units where a multidisciplinary approach and the concentration of numbers will allow controlled trials of the various therapeutic modalities. Furthermore, such units could through a national society for all doctors working with patients with cancer and other disorders of the oesphagus compare their results, coordinate clinical trials, and promote healthy discussion-to the ultimate benefit of the sufferers.

At the first British based international conference on disorders of the oesophagus recently held in Lancaster many specialists from various parts of the world submitted views similar to those expressed in this letter. Since then there has been a feeling among British doctors that the time has come to form such a national body. The publication of Mr Earlam's review is a timely reminder of our obligations to our patients and colleagues and we invite those interested in the concept of such a society to write to us.

A Watson

Royal Lancaster Infirmary, Lancaster LA1 4RP

\section{R Celestin}

Frenchay Hospital,
Bristol BS 16 1LE

1 Watson A. Therapeutic options and patient selection in the management of oesophageal carcinoma. oesophagus. London: Pitman, 1984

Dark JS, Mousalli H, Vaughan R. Surgical treatment of carcin

${ }^{3}$ McKeown KC. Carcinoma of the oesophagus. MR K Coll Surg Edinb 1979;24:253-74.

F R Coll Surg Edinb 1979;24:253-74. survival following resection, endoscopic intubation and surgical intubation in oesophageal carcinoma. Br $\mathcal{F}$ Surg 1982;69:585-8.

\section{Low osmolar contrast media}

SIR,-The implication of Professor Ronald G Grainger's leading article (21 July, p 144) and letter in Clinical Radiology $y^{1}$ is that non-ionic media should be used for all intravascular 